CUPAUAM 21, 1994, PP. 341-360

\title{
EL PATRIMONIO ARQUEOLÓGICO Y LA LEGISLACIÓN SOBRE EL SUELO
}

\author{
PILAR BARRACA DE RAMOS \\ Museo Arqueológico Nacional
}

\section{Resumen}

El patrimonio arqueológico es definido en la ley de PHE como todo bien susceptible de ser estudiado a través de metodología arqueológica, y está vinculado a la importante evolución urhanística que, bien regulada legislativamente, ha evolucionado en la última mitad del siglo XX. La ampliación urbana afecta a los bienes arqueológicos incluidos en su ámbito de aplicación, y de ahí surge la necesidad de reflexionar en torno a la legislación sobre el suelo, y adquirir el conocimiento necesario para una mejor protección de esos bienes culturales.

\section{Summary}

The Archaeological Heritage is defined by the Spanish Historical Heritage Law as any good susceptible to be studied though an archaeological method. And this Archaeological Heritage is tied in with the big town-planning developpement happened during the last fifty years, because the urbanization usually include it. This relationship leads to think over the ground legislation and adquire the cognizance to protect those cultural riches.

\section{INTRODUCCIÓN}

El objetivo primero de este trabajo se centró en la delimitación de la legislación del patrimonio arqueológico en relación con la legislación urbanística vigente. Se originó en el entorno correspondiente al curso de doctorado -El patrimonio Arqueológico Español: legislación y medidas para la defensa y control-, impartido en 1993 por la Dra. Lucas Pellicer. Su finalidad sería el debate en una de las clases de dicho curso ${ }^{1}$.

${ }^{1}$ Es de gran importancia la puesta en marcha de estos cursos, en la Universidad, pues hasta ahora sólo han merecido el interés de los organismos públicos y las personas relacionadas con las instituciones encargadas de la defensa del patrimonio histórico. Fuera de ellos, no se ha prestado la necesaria atención a la formación complementaria de los jóvenes arqueólogos, que debería incluir un conocimiento más profundo de todo aquello que rodea a la metodología arqueológica, una mayor información sobre el conocimiento legal, que permitan adecuar una mejor protección a nuestra Arqueología. 
Una de las bases analizadas durante ese período sería, a pesar de que inicialmente consideremos completa la protección legal de los restos arqueológicos, la necesidad de analizar la legislación complementaria que aportase nuevas lecturas en la defensa que se debe ofrecer a nuestro patrimonio. La puesta en práctica de un urbanismo desmesurado ha puesto en gran peligro al patrimonio arqueológico, y aunque la ley vigente de PHE intenta controlar y disminuir los desmanes provocados por el crecimiento urbano, estos se siguen produciendo. En gran medida, el desconocimiento de la legislación que existe sobre el uso del suelo y de las normas municipales, ayudan a la continuidad de estos desastres, y los profesionales del entorno de la Arqueología también contribuimos, al relegarnos en nuestro partidismo arqueológico y en nuestra ignorancia de la ley que puede amparamos.

Hecho este breve preliminar, entramos en el tema en cuestión. Se trata en este estudio de reflexionar sobre la normativa vigente que pueda afectar al patrimonio Arqueológico, en cualquiera de sus vertientes, y más en concreto con lo relacionado con las excavaciones arqueológicas. También hay un interés en introducirnos en aspectos legislativos de la arqueología, destacado por la falta de estudios que habitualmente se percibe en los profesionales de esta ciencia, y que a veces tiene graves consecuencias para la conservación del patrimonio Histórico. Para ello hay que considerar las leyes de Ordenación Urbana, las instrucciones de Régimen local, y la ley de Patrimonio Histórico Español, en los articulados que se refieran a la protección y conservación de diferentes parajes arqueológicos, y que por tanto, se relacionen entre sí. La Ley del Suelo se refiere fundamentalmente al territorio urbano, por lo que trataremos del ámbito del Patrimonio Arqueológico que esté incluido en recintos urbanos y, en consecuencia, de su relación con las corporaciones municipales.

El Patrimonio Arqueológico urbano depende de una compleja trama legislativa, sujeta a las normas elaboradas por diferentes instituciones, de las que dependerá su protección y conservación. Son, esencialmente, los Municipios y distintos Departamentos ministeriales, entre los que destacan el MOPU y el Ministerio de Cultura, a través de los organismos delegados en las Comunidades Autónomas.

En cuanto a método, la arqueología urbana se considera de total actualización para la puesta en vigor de las normas del $\mathrm{PH}$, en particular de las actuaciones derivadas de obras en inmuebles y otras de carácter público: asfaltado de calles, plantaciones en jardines y parques, planeamientos urbanos de ampliación municipal, etc. Por tanto, el auge creciente de la aplicación del método arqueológico en la ciudad, viene obligado por las continuas transformaciones y reconstrucciones que se están efectuando en casi todas nuestras ciudades. Efectivamente, la excavación arqueológica es muy importante para el conocimiento de las posibles estructuras preexistentes bajo el nivel urbano, y para una primera fase de conservación en trabajos que puede hacer en colaboración con las instituciones municipales y territoriales ${ }^{2}$.

${ }^{2}$ El auge de la arqueología urbana viene obligado por el aumento constructivo que se ha producido en las últimas décadas. No obstante, las publicaciones son escasa. Podemos considerar una serie de reuniones que tuvieron un gran eco, como las -Primeras jornadas de Arqueología en las ciudades actuales- (1983), o -Arqueologia de las ciudades modernas superpuestas a las antiguas. 
En otro sentido, se puede considerar que las normas dictadas por instituciones competentes, aunque no pertenezcan al ámbito de Cultura, constituyen los precedentes a que debe atenerse la arqueología urbana para su realización. Requiere y necesita cada vez más, una normativa específica a la que atenerse, puesto que actualmente se rige por reglas excesivamente generales, derivadas de la legislación para los planeamientos urbanos. Como se verá más adelante, esta legislación e incluso la más actual del Patrimonio Histórico, poco desarrollada, pueden interpretarse de diversas maneras (Avilés Perea, 1983).

\section{LA LEY DEL SUELO}

De manera muy sintética, se puede decir que la legislación sobre el suelo obedece a una necesidad de ordenación o planificación urbanística del territorio. Para ello utiliza los Planes, que se pueden definir como los instrumentos de esta ordenación, y que se pueden clasificar en Planes de tipo Nacional, Territorial o Municipal. Cada Plan dependerá del organismo competente, lo cual origina una serie de normativas sectoriales sobre el mismo territorio, que a veces son difíciles de coordinar y que, podemos considerar, han influido en el ordenamiento del PHE.

Fundamentalmente, se tratará el RDL 1/1992, vigente hoy, pero también será necesario tratar sus antecedentes directos, los Textos de 1956 y 1975, que como veremos tienen características comunes. El RDL 1/1992 sobre el Texto Refundido de la Ley sobre el Régimen del Suelo y Ordenación Urbana, responde a la necesidad de redactar las disposiciones vigentes sobre el suelo y su ordenación urbana, según se indica en la Ley 8/ 1990, de 25 de julio, sobre Reforma del Régimen Urbanístico y Valoraciones del Suelo. A esta Ley, hoy vigente, no vamos a referirnos, puesto que apenas menciona el tratamiento que debe darse a los bienes relacionados con el Patrimonio Histórico.

En general, y aplicado al PHE, podemos decir que su protección se contemplaba en la Legislación sobre el Suelo anterior a 1992, como objeto de las determinaciones de los Planes Generales de Ordenación Urbana, o municipales. Este tipo de Planes era básico en la legislación urbanística de los últimos treinta anos, puesto que no se había desarrollado el Plan Nacional de Ordenación, de rango superior, y que había sido dictado en 1956, y apenas se habían utilizado los Planes Territoriales. A este respecto, la Ley de 1992 manifiesta el aumento del planeamiento a un nivel superior al municipal, hecho que había quedado patente en la anterior legislación (1975), puesto que se había hecho poco uso de los Planes Directores Territoriales de Coordinación. Queremos decir con esto que, hasta 1992, los Planes Municipales de Ordenación Urbana habrían de ser los habituales y cotidianos en cada planeamiento o reforma urbanística.

Desde su primera redacción en 1956, la LS contiene normas relativas a la protección de los conjuntos históricos, que se refería estrictamente a medios urbanos. Pero esta protección se restringe claramente a bienes inmuebles contenidos en zonas ya urbani- 
zadas, en los que no se incluye el bien arqueológico. Consideramos este tipo de protección de gran interés, en referencia a determinados restos arqueológicos. Sería el caso de unas ruinas de cierta importancia como las de una ciudad romana, existentes fuera del ámbito urbano, por ejemplo, que no estarían consideradas como conjunto histórico, y no estarían sujetas a la protección que pudiera darle la LS, aunque sí estuviera protegido por la Ley de PHE. La situación de estas mismas ruinas, si estuvieran enclavadas en un casco urbano, sería diferente y además, no serían reconocidas como patrimonio arqueológico, sino como un monumento histórico o un bien de interés cultural (BIC).

Para comprender mejor el carácter de la protección de la legislación urbanística sobre nuestros bienes históricos, haría falta analizar la evolución seguida por la propia Arqueología Espanola, en la que no se ha reconocido la importancia de los bienes arqueológicos susceptibles de aparecer en suelo urbano hasta hace muy escasos años.

En principio, la LS se concibió y articuló para ordenar el crecimiento de la ciudad. Debemos reconocer que en 1956, el desarrollo de la arqueología espanola era todavía limitado y, en concreto, no llegaba a realizarse en las ciudades. Debido en gran manera a esa falta de previsión, no se contempla en la LS ningún tipo de normativa referida a las actuaciones arqueológicas. La legislación entonces vigente para el Patrimonio Histórico Arqueológico, el Reglamento vigente de 1912 y la Ley de 1933 junto con el Reglamento de 1936, no regulaban el control del posible patrimonio arqueológico existente en el subsuelo de las ciudades actuales. Sí se conocían vestigios antiguos en nuestras ciudades, pero no se les concedía mayor importancia y el desarrollo urbano era por otra parte, mínimo, en el momento en que se realizaron estas leyes. En 1975, momento en que el proceso de expansión urbana se ha detenido, comienza una nueva etapa en el proceso urbanista que consiste en la conservación del patrimonio existente. Para ello, se tuvo que desarrollar un estudio detenido de todas las competencias asumibles en la urbanización correspondiente y de los grados de conservación que se deberían aplicar.

En referencia a las obligaciones definidas para los distintos ministerios, se puede decir que ya desde su precedente de 1956, la LS desarrolla un artículo que se refiere a las competencias asumibles por otros ministerios en cuanto al ejercicio de los Planes, que podian haber sido recogidas por Cultura, al haber dejado un amplio y sutil margen de actuación. En el Texto de 1975, vuelve a aparecer un artículo similar, aunque más detallado, es el Art. 57.2:

-La aprobación de los Planes no limitará las facultades que correspondan a los distintos Departamentos ministeriales para el ejercicio, de acuerdo con las previsiones del Plan, de sus competencias, según la legislación aplicable por razón de materia.

De las mismas características es el artículo 141 del RDL 1/1992, hoy vigente:

La ejecución de los planes de ordenación corresponde al Estado, a las Comunidades Autónomas y a las Entidades locales en sus respectivas esferas de actuación, sin perjuicio de 
la atribución de competencias a órganos específicos y de la participación de los particulares en dicha ejecución en los términos establecidos por la legislación aplicable.*

Entre las normas más específicas que se dictan en 1975 para la protección del Patrimonio Histórico destaca el art. 73:

-La construcciones en lugares inmediatos o que formen parte de un grupo de edificios de carácter histórico, arqueológico, típico o tradicional, habrán de armonizar con el mismo, o cuando, sin existir conjunto de edificios, hubiera alguno de gran importancia o calidad de los caracteres indicados.

Por primera vez en estas normativas, se utiliza el término "arqueológico" , aunque no referido a yacimientos, sino a edificios de carácter arqueológico. Ahora bien, un edificio de carácter arqueológico es un resto de un bien excavado en el pasado, o simplemente las ruinas de alguna estructura mantenida en el tiempo. Estamos por tanto, en el límite de la protección que el Ministerio de Obras Públicas puede conceder a un bien arqueológico y que, en su totalidad, debe ser realizada por el Departamento correspondiente, según el art. 57.2 del Texto de 1975, y que en este caso, corresponde al Ministerio de Cultura o a los organismos competentes de las comunidades autónomas.

También se podría considerar, aunque no es muy probable, que al redactar este artículo, los legisladores ya se planteaban el encuentro de yacimientos arqueológicos al realizar el ensanche de las ciudades. En cualquier caso, si Cultura desde su primer reglamento de 1912 no había previsto tal situación, poco se debería esperar de otros ministerios.

En síntesis, podemos considerar que la LS, en las redacciones anteriores a 1992, no contempla en ningún momento las actuaciones, competencias, etc. del subsuelo de los edificios, al analizar el carácter de protección que debe asignársele al Patrimonio Histórico existente en las ciudades. Se refiere únicamente al carácter de monumentalidad de algunos edificios y a todos aquellos inmuebles integrantes de conjuntos históricos, que actualmente son considerados BIC.

\section{REAL DECRETO LEGISLATTVO 1/1992}

El RDL 1/1992 sobre el Texto Refundido de la Ley sobre el Régimen del Suelo y Ordenación Urbana, palia en parte la falta de normativa protectora sobre el Patrimonio Arqueológico que se había detectado anteriormente. Veamos su ordenación jurídica al respecto:

En cuanto a los derechos y deberes de los propietarios, hay que destacar el artículo 21 del Texto de 1992: 
- Punto 1. Los propietarios de toda clase de terrenos y construcciones deberán destinarlos efectivamente al uso en cada caso establecido por el planeamiento urbanístico y mantenerlos en condiciones de seguridad, salubridad y ornato püblico. Quedarán sujetos igualmente al cumplimiento de las normas sobre protección del medio ambiente y de los patrimonios arquitectónicos y arqueológicos, y sobre rehabilitación urbana.

Específicamente se habla ya de Patrimonio Arqueológico, poniéndolo en relación con la obligatoriedad de su protección por parte de cada propietario. Asimismo, queda implícita la responsabilidad que tendrá el propietario, en caso de destrucción o deterioro de una zona arqueológica, como se verá en la legislación correspondiente a la expropiación.

- Punto 2. - El coste de las obras necesarias en virtud de lo dispuesto en el número anterior se sufragará por los propietarios o la Administración, en los términos que establezca la legislación aplicable».

Este párrafo, que se refiere a la adjudicación del coste de las obras necesarias, tiene su ampliación en la Ley PHE según veremos más adelante, con la definición del uno por ciento del presupuesto total de la obra.

El artículo 68, relativo a Planes Territoriales de Coordinación, regula su objeto y contenido, y particularmente en su párrafo C) señala las determinaciones que deberán contener estos Planes con respecto al Patrimonio Histórico, y que responden a la adopción de las medidas necesarias de protección en orden a ala defensa, mejora, desarrollo o renovación del medio ambiente natural y del Patrimonio Histórico".

De manera similar, el artículo 72, relativo al Plan General Municipal de Ordenación, señala las determinaciones que deberán contener estos planes y también, señala en su párrafo F) que serán necesarias medidas de protección para la defensa de conjuntos urbanos e históricos. Aunque esta norma es menos precisa, alude sin embargo a la legislación específica que sea de aplicación en cada supuesto.

En este sentido, el artículo 84 del texto de 1992, referido a los Planes Especiales es de gran interés para el Patrimonio Arqueológico. Define las clases de Planes Especiales. Su importancia radica, fundamentalmente, en que define la existencia de estos planes sin la necesidad de aprobación de los Planes Generales de Ordenación, tanto Territoriales como Municipales. Se subraya, por tanto, que los Planes Especiales se pueden poner en marcha de forma autónoma.

Entre los fines que puedan ser considerados para que surja un Plan Especial, el RDL 1/1992 declara:

- Punto 1, referido a Planes Territoriales.

- Párrafo b del punto 1: "Ordenación de recintos y conjuntos bistórico-artísticos, y protección del paisaje, de las vias de comunicación, del suelo y subsuelo, del medio urbano, nural y natural, para su conservación y mejora en determinados lugares.

- Párrafo c del punto 1: "Cualesquiera otras finalidades análogas. 
En el párrafo b se deja abierto un amplio campo de protección, en el que puede contemplarse el Patrimonio Arqueológico desconocido, inmerso en la palabra "subsuelo" e incluido, a los efectos que nos interesan, en la expresión "medio urbano". Además, determina que la ordenación de los Planes Especiales está dirigida a la conservación y mejora en determinados lugares, sin especificar, lo que podemos entender como la apertura en el campo de la conservación a la inclusión de posibles estructuras aparecidas en yacimientos urbanos. También, al exponer la expresión "medio rural y natural", la LS amplía su entorno protector pues ya no se limita únicamente a los medios urbanos. Incluye todos aquellos tipos de suelos susceptibles de ser urbanizados y que, por tanto, se encuentren en un entorno rural. Se puede considerar que esta característica supone una gran diferencia con las leyes predecesoras de 1956 y 1975.

En otro sentido, hay que considerar que la definición de subsuelo y propiedad del mismo, no existe, y en el medio urbano es bastante ambigua. El resto arqueológico hallado en el subsuelo rural, es un bien cultural por su naturaleza y no por la profundidad en que haya sido hallado, siendo considerado propiedad del dueño del terreno al que se le aplican determinados artículos de la ley 16/1985. Esto, en términos generales es válido para el medio rural pero, en el medio urbano, el subsuelo ya es propiedad del Estado. Por otro lado, una excavación realizada en una zona urbana, puede ofrecer restos a poca profundidad siendo subsuelo porque está bajo suelo urbano, pero esas cotas pueden ser consideradas legalmente como bajos de cimentación o sótanos de edificios ya existentes, que no es considerado, por tanto, subsuelo, en el sentido estricto de esta palabra. Habría que analizar quién es el propietario de este suelo ya urbanizado, contenedor de los restos arqueológicos.

Asimismo, el punto 2 que está referido a los Planes Municipales, hace hincapié en la protección de este Patrimonio, al señalar en su párrafo d: "Protección de los elementos $a$ que se alude en el párrafo $b$ del apartado anterior. Aquí se refiere a la posibilidad de creación de un Plan Especial sin la necesidad de aprobación de un Plan Parcial dentro de las previsiones de los Planes Generales Municipales de Ordenación. También en este apartado, podemos considerar el párrafo b: "Ordenación y protección de recintos y conjuntos arquitectónicos, bistóricos y artísticos", puesto que de manera más específica se refiere al patrimonio histórico y en prevención, un Plan Especial dedicado a esta ordenación puede acoger un supuesto yacimiento arqueológico.

Sin embargo y para dejar muy claro el deber de protección que cada Municipio debe dar al patrimonio arqueológico, con anterioridad a este RDL de 1992 ya existía la normativa de 1985 de PHE. El art. 20.1 de la Ley 16/1985 de Patrimonio Histórico Español define, en relación con la existencia de zonas arqueológicas en un medio urbano:

-La declaración de una Zona Arqueológica como BIC, determinará la obligación para el municipio o municipios en que se encontrare de redactar un Plan Especial de Protección del área afectada por la declaración u otro instrumento de planeamiento de los previstos en la legislación urbanística que cumpla, en todo caso, las exigencias de esta Ley 
establecidas. ... La obligatoriedad de dicho Plan no podrä excusarse en la preexistencia de otro planeamiento contradictorio con la protección, ni en la inexistencia previa de planeamiento general.

El artículo 86 de la LS referido a los Planes Especiales de protección del paisaje, también observa una redacción a la que puede acogerse un bien arqueológico: La protección del paisaje, para conservar determinados lugares o perspectivas del territorio nacional en cuanto constituye objeto de planeamiento especial, se referirá entre otros, a estos aspectos:

c) Edificios aislados que se distinguen por su emplazamiento o belleza arquitectónica y parque y jardines destacados por la hermosura, disposición artística, trascendencia bistórica..."

Esta descripción que recuerda bastante a la incluida como paraje pintoresco en la ley de 1926 de Protección y Conservación de la Riqueza Artística, o a la ley de 1985 de Patrimonio Histórico cuando define que es un Sitio y Jardines Históricos en su artículo 15 , hace que queramos incluir en este tipo de protección a una serie de bienes arqueológicos como pueden ser las pinturas rupestres. Este tipo de bienes son susceptibles de ser consideradas como patrimonio arqueológico, por estar inmersos en zonas consideradas como tal.

En cuanto al tema de la expropiación, que también se señalará en la Ley de PHE, este RDL 1/1992 trata los supuestos expropiatorios en el artículo 206, indicando su aplicación:

d) Para la constitución o aplicación del Patrimonio Municipal del Suelo u otros patrimonios públicos de suelo.

f) Por incumplimiento de la función social de la propiedad.

g) En los demás supuestos legalmente previstos.

En el caso del párrafo f) que sería el menos claro, el artículo 207 desarrolla las aclaraciones oportunas de su aplicación:

a) Por inobservancia de los plazos establecidos para la urbanización de los terrenos y su edificación o, en general, de los deberes básicos establecidos en esta Ley, cuando no se opte por la aplicación del régimen de venta forzosa.

Como se puede comprobar, el campo queda abierto a varias facetas, al incluir el término de deberes básicos y su inobservancia. Entre otros deberes, a nosotros nos inte- 
resa el que alude a la responsabilidad de la protección del patrimonio arqueológico por parte de los propietarios, artículo 21 ya señalado.

\section{LEY 16/1985 DE PATRIMONIO HISTÓRICO ESPAÑOL}

La Ley 16/1985 y su Real Decreto parcial de Desarrollo 111/1986 dedican, por primera vez en la legislación del patrimonio histórico, una gran atención a los planeamientos urbanos y a la protección que deben propiciar al Patrimonio Histórico. Aquí solo se verán los artículos que están más directamente relacionados con la legislación urbanística, y a partir de ahí, se intentará comentar aquellos que estén más vinculados con el patrimonio arqueológico. Puesto que, con anterioridad a esta Ley, apenas se había prestado atención al planeamiento urbanístico en relación con el Patrimonio Histórico, no se puede tampoco incidir especialmente en normas y precedentes legislativos sobre el patrimonio arqueológico, que no existen.

Barrero $(1990)^{3}$ en un exhaustivo estudio sobre las connotaciones legales del Patrimonio Histórico, llega a entrever la confusa definición del Patrimonio Arqueológico al señalar como el bien arqueológico es únicamente el que es susceptible de ser estudiado con método arqueológico. A partir de esta base, es difícil aplicar una legislación protectora a un patrimonio dudosamente definido. Por otra parte, nuestra ley de PHE se limita a adoptar una serie de normas generales para la protección del Patrimonio, no para su ejecución, que es precisamente donde se planean los problemas (Barrero, 1990: 608). Señala, no obstante, para el caso específico que estamos tratando y en relación con el derecho urbanístico, la normativa vigente de PHE sobre actuaciones sujetas a autorización previa. Se trata de los artículos 20.3 y 22, donde se refiere en concreto a las obras a realizar en zonas arqueológicas. El término "obra" abarca todas las actuaciones que sean realizadas sobre el bien en cuestión, en este caso sobre el yacimiento arqueológico o el edificio de carácter arqueológico.

Art. 20.3: "Hasta la aprobación definitiva de dicho Plan, el otorgamiento de licencias o la ejecución de las otorgadas antes de incoarse el expediente declarativo de la Zona Arqueológica, precisará resolución favorable de la Administración competente para la protección de los bienes afectados y, en todo caso, no se permitirân alineaciones nuevas, alteraciones en la edificabilidad, parcelaciones ni agregaciones.

Este artículo es de gran importancia, ya que es claro y firme en cuanto a la decisión de no permitir ningún tipo de construcción en una zona supuestamente arqueológica o

${ }^{3}$ En su libro sobre la -Ordenación jurídica del Patrimonio Histórico Español-. C. Barrero analiza pormenorizadamente la legislación existente en 1990 en relación con el suelo y el patrimonio histórico. Sin embargo, no hace ninguna mención a la nueva Ley del Suelo promulgada en ese mismo año, que además habría de ser sensiblemente reformada en el Real Decreto Legislativo de 1992. 
en vías de serlo. Se impide la concesión de licencias por parte de los Ayuntamientos, y la Administración competente que en este caso es la Comunidad Autónoma, debe dictar resolución favorable. La puesta en vigor de esta norma no es nada fácil, ya que puede ocasionar muchos perjuicios y daños económicos de gran cuantía, que deben ser previstos antes de aplicarla. Hay varios ejemplos recientes que se pueden citar, en Madrid, como la construcción de las torres Kio, cuyas obras estuvieron paralizadas durante meses con el fin de determinar sí debía incoarse el expediente relativo a Zona Arqueológica.

Art. 22.1: "Cualquier obra o remoción de terreno que se proyecte realizar en un Sitio Histórico o Zona Arqueológica declarados BIC, deberá ser declarada por la Administración competente para la protección de dichos bienes, que podrá, antes de otorgar la autorización, ordenar la realización de prospecciones y, en su caso, excavaciones arqueológicas, de acuerdo con lo dispuesto en el Título $V$ de la presente Ley.

Este artículo quiere evitar la destrucción, prácticamente generalizada, de yacimientos arqueológicos al efectuar cualquier tipo de obra. No especifica sí en suelo urbano o rural, pero interesa a los efectos de no dejar desamparado ningún terreno urbano susceptible de estar incluido en una Zona Arqueológica, y que pueda ser objeto de un Plan de Urbanización.

No obstante, y a pesar de estar mínimamente regulada la protección de las Zonas Arqueológicas, su desconocimiento general, debido a la falta de estudios previos, prospecciones, o simplemente a la desidia de los organismos o personas afectadas, puede provocar grandes pérdidas del patrimonio arqueológico. Este sería el ejemplo conocido de Cercadilla, en Córdoba: las obras realizadas en relación con la construcción de una vía férrea en 1991, se llevaron por delante importantes restos arqueológicos. La responsabilidad de este suceso no fue aclarada.

A consecuencia del uso del método arqueológico, de manera previsible o no, pueden aparecer restos de considerable importancia que obligarán al arqueólogo a proponer sistemas de conservación y de protección. Este será el caso de las estructuras arquitectónicas susceptibles de aparecer en el medio urbano, que ya forman parte de un BIC y pueden ser elementos que requieran por sí mismos, la elaboración de un Plan Especial. Así se expresa la ley PHE al definir el Patrimonio Arqueológico, en el art. 40.1; en la declaración de Zonas Arqueológicas, art. 14.2; y en la declaración de elaboración de Planes Especiales, art. 20.1.

En otro orden, este articulado se puede tomar como base en la realización de estudios previos para la realización de obras públicas. Estos estudios que ahora llamamos de Impacto Ambiental, por la repercusión que pueden tener en su entorno, son perfectamente idóneos para proceder a una protección efectiva de nuestro patrimonio. A este respecto, en la ciudad, prácticamente se ha puesto como norma la realización de una prospección en cada solar edificable. Aunque no esté directamente relacionado, sí tiene alguna conexión el Art. 22.2: 
-Queda prohibida la colocación de cualquier caso de publicidad comercial, así como de cables, antenas y conducciones aparentes en las Zonas Arqueológicas*.

Este punto apenas se cumple, ya que en general contradice las normativas municipales, como ocurre en el caso de la colocación de cables o conducciones. Además, el hecho de que incluya la palabra "aparentes" obliga en muchos casos a hacer obras de metido de dichas conducciones bajo el suelo, siendo estas obras más perjudiciales que la mera vista de las conducciones en el exterior. El ejemplo que conocemos en el estudio de los yacimientos arqueológicos urbanos, es el hecho frecuente de encontrar los niveles más altos cortados por canales o estructuras hechos para conducciones o cableados de alta tensión, algunos de fechas muy recientes.

Ya entrada en vigor esta Ley de PHE, que no ha tenido mucha difusión fuera del ámbito cultural, el tipo de obras señaladas se sigue realizando con la mínima protección para el patrimonio arqueológico, y afecta fundamentalmente a todas aquellas ciudades que no han tenido unas reformas muy significativas hasta hace pocos anos, y cuyo subsuelo mantiene todavía estructuras que pueden ser significativas.

El siguiente párrafo supone una imposición a los municipios que tienen, entre otras competencias, la de asignar las licencias de obras:

Art. 23.1: „No podrân otorgarse licencias para la realización de obras que conforme a lo previsto en la presente Ley requieran cualquier autorización administrativa, hasta que esta haya sido concedida."

Muy similar al artículo 20.3, el contenido de este párrafo se refiere en general, a cualquier tipo de obras. No se está, pues, a la espera de ningún Plan Especial y a pesar de ello, la Administración quiere evitar cualquier destrucción de una posible zona de interés cultural. No obstante y en prevención de que se contravenga este mandato, se redacta en el siguiente las responsabilidades a que habrá lugar por parte de los infractores'. Su claridad obvia cualquier comentario:

Art. 23.2: "Las obras realizadas sin cumplir lo establecido en el apartado anterior serán ilegales y los ayuntamientos o, en su caso, la Administración competente en materia de protección del PHE podrán ordenar su reconstrucción o demolición con cargo al responsable de la infracción en los términos previstos por la legislación urbanística.-

Aquí, de manera concreta, se alude a la legislación urbanística vigente, que será la que determine el tipo de infracción y quién es el infractor. Asimismo, al hablar de la Administración competente se puede referir al departamento ministerial correspondiente, a la Comunidad Autónoma o al municipio responsable, además del Ministerio de Cultura como oidor. 
El tema de la expropiación está tratado en ambas leyes, aunque la Ley de PHE lo regula de manera más general. El artículo 25 está relacionado específicamente con inmuebles integrantes del PHE, y alude a las competencias de la legislación urbanística, por lo que no atiende directamente al tema que nos ocupa. Más específico es el artículo 37 , que interesa a este trabajo pues puede afectar directamente a un bien de carácter arqueológico:

1. La Administración competente podrá impedir un derribo y suspender cualquier tipo de obra o intervención en un bien declarado BIC.

2. - Igualmente, podrá actuar de ese modo, aunque no se haya producido dicha cleclaración, siempre que aprecie la concurrencia de alguno de los valores a que bace mención el artículo $10^{\circ}$ de esta Ley.

3. -Será causa justificativa de interés social para la expropiación por la Administración competente de los bienes afectados por una declaración de IC el peligro de destrucción o deterioro, o un uso incompatible con sus valores. Podrán expropiarse por igual causa los inmuebles que impidan o perturben la contemplación de los bienes afectados por la declaración de IC o den lugar a riesgos para los mismos.

Aunque con otro carácter, creemos necesario aludir aquí a un punto que interesa. Es aquel que está en relación con la conservación de estructuras arquitectónicas incluidas en el medio urbano, que forman parte del Patrimonio Arqueológico por ser ruinas, y que son susceptibles de rehabilitación. Este es el caso, por ejemplo, del teatro romano de Sagunto. A este respecto, la Ley de PHE se expresa en el artículo 39, puntos 1, 2 y 3 , indicando la obligación de los poderes públicos a mantener la conservación y mejora de estos bienes, a evitar los intentos de reconstrucción, y a restaurar respetando las aportaciones de épocas precedentes.

En otro sentido, el artículo 39 aborda el tema de las competencias por parte de otros poderes públicos de la Administración. Señala la obligatoriedad, de todos ellos, a procurar la conservación, mejora y consolidación de los bienes integrantes del patrimonio histórico.

Existe también en la ley PHE una declaración de las infracciones administrativas y de las sanciones a que den lugar. El hecho de que se aluda únicamente al artículo 22, que se refiere específicamente a Zonas Arqueológicas, supone una falta preventiva de protección hacia cualquier yacimiento arqueológico, porque sólo serán infracciones las obras realizadas en Zonas Arqueológicas. A pesar de que todo yacimiento, por definición en esta Ley supone la consideración de BIC, para ser considerado o incluido en la categoría de Zona Arqueológica, debe ser previamente conocido e inventariado como BIC. Por tanto, su desconocimiento le excluye automáticamente de la protección que se derivaría de su inclusión en el Catálogo correspondiente. 
Además, se puede entender en este párrafo 76.1, que todas las obras que, de manera accidental, se encuentran en sus remociones un yacimiento y lo están alterando o destruyendo, de manera inconsciente, no constituyen ningún tipo de infracción.

Art. 76.1: Salvo que sean constitutivos de delito, los hechos que a continuación se mencionan constituyen infracciones administrativas que serân sancionadas conforme a lo dispuesto en este artículo:

d) La realización de obras en Sitios Históricos o Zonas Arqueológicas sin la autorización exigida por el artículo 22".

Art. 76.2: -Cuando la lesión al Patrimonio Español ocasionada por las infracciones a que se refiere el apartado anterior sea valorable económicamente, la infracción será sancionada con multa del tanto al cuádruplo del valor del daño causado.

Art. 76.3: "En los demás casos se impondrán las siguientes sanciones:

B) Multa de basta 25.000 .000 de pesetas en el supuesto d) del apartado 1 .

A este último punto se agarrarán aquellos que, en líneas generales, contravengan la legislación y ocasionen daños al patrimonio arqueológico, pues la valoración de estos daños es prácticamente imposible cuando el yacimiento no se conoce en su extensión, ni tampoco la magnitud de lo desaparecido. Por otra parte, la multa de hasta veinticinco millones de pesetas, hoy día, se puede considerar risible.

En la Disposición Transitoria Sexta-Punto 2 se recoge la normativa para Los Planes Especiales que estuviesen en marcha antes de la entrada en vigor de la Ley 16/1985 en cuanto a los Conjuntos Históricos, que sin embargo, ya hemos visto que pueden tener bastante relación con las Zonas Arqueológicas:

-En los Conjuntos Históricos ya declarados que dispongan de un Plan Especial de Protección u otro instrumento de planeamiento del área afectada por la declaración, aprobado con anterioridad a la entrada en vigor de esta Ley, la autorización de obras se regirá por lo dispuesto en el artículo 20.3 hasta que no se haya obtenido de la Administración competente el informe favorable sobre el instrumento de planeamiento a aplicar. A estos efectos se entenderá emitido informe favorable transcurrido un año desde la presentación del Plan, sin que baya recaido resolución expresa.-

\section{REAL DECRETO 111/1986 DE DESARROLLO PARCIAL DE LA LEY 16/1985}

De igual manera, en relación con las obras públicas o realizadas en entornos que supongan la consideración de patrimonio histórico, existen una medidas de fomento que, en general, se describen en el Título IV del RD 111/1986: 
Art. 58.1: "En el presupuesto de cada obra publica, financiada total o parcialmente por el Estado, se incluirá una partida equivalente al menos al uno por ciento de los fondos que sean aportación estatal con destino a financiar trabajos de conservación o enriquecimiento del PHE o de fomento de la creatividad artística, con preferencia en la propia obra o en su inmediato entorno. Se entenderá cumplida esta exigencia cuando las obras públicas tengan por objeto actuaciones de reparación o conservación en bienes inmuebles integrantes del PHE

Esta medida es de gran importancia pues supone la posibilidad de realización de obras arqueológicas incluidas en la obra pública, cuyo fin sea la documentación de los trabajos de conservación y el propio enriquecimiento del patrimonio. Ocurre que en la mayor parte de las obras de rehabilitación y conservación de inmuebles históricos, que normalmente están subvencionadas por el Estado, no se dedica ese tanto por ciento a la documentación señalada. Esta circunstancia no es nada extraña por el desconocimiento habitual que hay de la Ley de PHE.

El siguiente punto de este artículo se dedica a las exclusiones de esta norma.

El artículo 58.3 indica la obligatoriedad de presentar los proyectos a través del MC o del MOPU, siempre instando a dar cuenta al MC.

El artículo 59.1 es prácticamente igual al 58.1, aunque referido a las obras públicas explotadas o construidas por particulares y sin financiación estatal. Sin embargo obliga, de la misma manera, a destinar el uno por ciento del presupuesto total a la financiación de trabajos definidos en el artículo anterior. En este caso, el Estado deja una libre vía de elección para hacer efectivo el destino del uno por ciento, según se especifica en los puntos 2 y 3 de este mismo artículo. El ingreso se puede realizar directamente en el Tesoro Público, que será utilizado por el Consejo de Patrimonio Histórico en sus Planes de conservación, o bien se puede hacer, realizando los trabajos de conservación en la obra o en su entorno.

Muy importante de cara a la actuación de los medios particulares es la medida de fomento que se indica en el artículo 61.1 del RD 111/1986:

-Los inmuebles comprendidos en una Zona Arqueológica e incluidos como objeto de especial protección en el instrumento urbanistico a que se refiere el artículo 20 de la Ley 16. 1985 tendrán la consideración de inscritos en el registro de BIC a los efectos fiscales previstos en los art. 70, 71 y 73 de dicha Ley.

Esos artículos tratan de deducciones y otras medidas de fomento, siempre de tipo fiscal, relacionadas con distintos tipos de impuestos: Sociedades, Patrimonio, Sucesiones, Renta de Personas Físicas.

Hacía falta insistir en las medidas de fomento aplicables a los inmuebles comprendidos en Zonas Arqueológicas, pues la Ley 16/1985 en su artículo 69.2 indica que aen el 
caso de Zonas Arqueológicas, solo se consideran inscritos los inmuebles comprendidos en ellos que reúnan las condiciones que reglamentariamente se establezcan". Por tanto, no todos los inmuebles comprendidos en ámbitos arqueológicos son susceptibles de ser declarados BIC.

\section{LEGISLACIÓN MUNICIPAL}

No podemos dejar a los Ayuntamientos a un lado, puesto que detentan una gran parte de los instrumentos de protección del patrimonio arqueológico. Este hecho se puede considerar tanto real como legal. Su legalidad a efectos de leyes superiores viene señalada en la propia Ley del Suelo, por los Planeamientos de Ordenación Urbana que, como hemos visto, son los utilizados más frecuentemente.

En cuanto a la legislación en materia de cultura, podemos acudir a los precedentes de la ley vigente y ya encontramos normas en la ley de 1933, sobre custodia y conservación del Patrimonio Histórico Artístico por parte de los municipios. Los artículos 25 y 36 son el mejor ejemplo de la preocupación existente sobre la protección de los bienes históricos. En el artículo 25 se procura la cooperación con la Administración Local, tanto Ayuntamientos como Diputaciones, indicando que los costos derivados de la conservación y consolidación de los monumentos de cada localidad, dependería de los mismos. El artículo 36 incide en la obligatoriedad de los municipios en la custodia del patrimonio histórico, indicando el grado de inspección que deben asumir los propios municipios para evitar la degradación del bien histórico.

La propia legislación municipal ha contenido desde la creación de estas corporaciones, en 1824, normas relativas a la protección de los conjuntos histórico-artísticos. La Ley de Régimen Local de 1955, vigente hasta 1985, ya definía en el artículo 178 el cuidado que habría de darse en el plan de urbanización con respecto a los aspectos históricos de las zonas adaptadas por obras.

Actualmente, los Ayuntamientos se rigen por la Ley Básica de Régimen Local, de 1985 , en que sus competencias en materia de cultura se remiten a la legislación estatal y, por tanto, sus competencias quedan relegadas a lo que dicte la norma superior. Sin embargo, puede considerarse que en esencia, no ha cambiado la actuación de los Ayuntamientos, puesto que siguen colaborando y actuando directamente en el ámbito de los planeamientos urbanos. Y en su relación con la legislación urbanística, los municipios actúan a través de Patrimonios Municipales del Suelo, cuya función es encauzar el desarrollo urbanístico y cuyos bienes son calificados de dominio público.

Tanto en la Ley 16/1985 como en el RDL 1/1992 de LS, se desarrollan normas relativas a las instituciones municipales, tendentes a la protección del Patrimonio Arqueológico, que se han visto anteriormente. Se trata sobre todo en la Ley 16/1985 de PHE, del artículo 7 donde se definen las competencias de los ayuntamientos en materia de 
cultura, y otras menciones como el artículo 20.1, ya comentado, sobre los Planes Especiales de protección. En cuanto al RDL de 1992, destacan los artículos 72 y 84.2, relativos al Plan General Municipal de Ordenación y a los Planes Especiales, respectivamente.

Referente a la relación que mantienen los Ayuntamientos con la Arqueología, podemos considerar que viene derivada de la existencia del patrimonio arqueológico en suelo urbano y, en consecuencia, de la utilización de una metodología arqueológica para su estudio y conservación. Este aspecto es muy importante, puesto que toda actuación arqueológica efectuada en un medio urbano, es considerada por un lado como obra, y por otro, como una remoción de un entorno urbano y que puede afectar a la evolución estética del medio en que se desarrolle.

Además toda excavación arqueológica necesitará la licencia de obras correspondiente al municipio en que se quiera desarrollar, además de los permisos necesarios de la Administración competente en arqueología. He aquí un punto interesante, puesto que de forma totalmente diferente, las excavaciones realizadas en el medio rural, no necesitan de permisos municipales.

Queda señalar que la importancia de este patrimonio arqueológico existente en el subsuelo de muchas ciudades y ámbitos urbanos, es cada vez reconocida en mayor grado por los Ayuntamientos. Por ello, se ha visto necesaria la creación de servicios o departamentos de arqueología dependientes de estas corporaciones. Estos servicios tienen como misión esencial, velar por la conservación de ese patrimonio y evitar su posible destrucción. Al mismo tiempo, el incremento del material arqueológico como resultado de las actuaciones de estos servicios de arqueología, lleva consigo la creación de pequeños museos, cuya finalidad principal es también la conservación del patrimonio mueble arqueológico.

\section{SÍNTESIS DEL TRABAJO}

En estas brevísimas consideraciones sobre la legislación aplicable al patrimonio arqueológico, hemos podido entresacar varios puntos de gran interés:

En primer lugar, cabe señalar que por primera vez en la historia legislativa del $\mathrm{Pa}$ trimonio Histórico, se regula la normativa necesaria para la protección de determinados bienes, cuyo ámbito de protección no dependía solo del Ministerio de Cultura o afines. Nos referimos a que se ha reconocido la competencia de otras Administraciones en materia de bienes históricos, y se ha regulado la nueva ley conforme a esta situación.

Efectivamente, desde antiguo ha existido una gran preocupación por mantener una defensa de los bienes inmuebles que se hallaban en el ámbito de la ciudad. Esta defensa se hallaba en el ánimo de los ministerios encargados de Obras Públicas y de Fomento al Arte o a la Cultura, y en los municipios que las contenían. Pero hasta ahora la situación 
era partidista, dependiendo de la actuación de cada Administración, que no habían regulado una normativa común.

La Ley vigente aborda las relaciones entre urbanismo y patrimonio histórico que, hasta ahora, habían sido difíciles. Enfoca con un nuevo carácter las competencias, en distintos ámbitos, sobre los conjuntos urbanos contenedores de bienes históricos.

En otro orden y referido a la defensa de los yacimientos arqueológicos inmersos en los núcleos urbanos, también ha habido una mejora sustancial. Puesto que, anteriormente no se concebía la excavación urbana en los conjuntos históricos, no existía una protección específica en nuestra legislación para el patrimonio arqueológico que se halla en esta situación. Actualmente, estos conjuntos históricos pueden, en muchos casos, ponerse en relación directa con el Patrimonio Arqueológico, tanto por su naturaleza como por el modo de su inclusión en el Catálogo del Patrimonio Histórico Español.

Otro avance importante que supone la nueva Ley de PHE, es la inclusión de medidas de fomento en relación con el fisco, y de utilización de los presupuestos para costear trabajos de conservación, que se ha puesto en relación directa con el patrimonio arqueológico. Esto ha supuesto la consideración de otros ministerios hacia el patrimonio histórico, debiendo incluir en sus normas y regulaciones el capítulo correspondiente a la planificación, ejecución, etc. de obras y economía relacionadas con nuestro patrimonio cultural y en concreto, con el arqueológico.

En cuanto a la legislación urbanística podemos señalar varios aspectos:

En primer lugar, hay que considerar la abundante legislación existente, que ha estado en vigor hasta la aparición de la Ley de 1990 y su Decreto de desarrollo de 1992. Sin embargo, esta circunstancia que se debía a la falta de una derogación expresa del articulado anterior, no se ha terminado de solventar con la ley vigente, de 1990, de la que deriva el actual RDL de 1992. Para nosotros será este Decreto el fundamental, puesto que contiene el articulado necesario para la defensa de nuestro patrimonio, pero hay que hacer notar que este desarrollo puede superar a la propia Ley en algunos aspectos. La lectura detenida de ambos textos hace ver algunas contradicciones en que puede incurrir, y que pueden repercutir directamente en el ámbito de las competencias debidas a cada Administración.

Podemos destacar como una nota importante que, en la normativa relativa a la Ley del Suelo, aparece desde 1975 la palabra Arqueológico y la determinación de proceder a la protección del Patrimonio Arqueológico. Es importante porque define unas características concretas a la protección y cuidado que determina la ejecución de los planeamientos.

Actualmente, las leyes del Suelo ya no se limitan únicamente al cuidado de conjuntos históricos, que tratarían en esencia de inmuebles, sino que se deja abierto el campo de la existencia de yacimientos arqueológicos. Aplicando debidamente esta le- 
gislación se puede impedir la destrucción de Zonas Arqueológicas incluidas en esos conjuntos históricos, o incluso fuera de ellos.

Se puede señalar, asimismo, que se percibe en esta nueva ley del Suelo (1992) un interés por salir del planeamiento específicamente urbano, es decir, que se plantea la urbanización y el urbanismo de zonas rurales, urbanizadas o no, y de las ampliaciones urbanas. No se trata sólo de un ensanche urbano, tal como se concebía en las primeras redacciones de la Ley, en el siglo pasado. Y esto afecta notablemente a nuestro patrimonio arqueológico, hecho que parece haber sido notado por los responsables de la legislación urbanística.

En cuanto a los municipios de gran tamaño, resalta la importancia de los planeamientos desde el siglo XIX, y el consecuente desarrollo que se ha producido. Por otra parte, las construcciones urbanas se han multiplicado en los últimos años de manera espectacular, y era totalmente necesario modernizar el sistema de planeamientos, con las consecuencias derivadas de su aplicación. Con ello queremos significar que, a pesar de su importancia, no se deben considerar como el punto de partida o un hito destacable en el siglo XX, para el comienzo de su relación con la Arqueología.

El patrimonio arqueológico no ha sido el único relegado: en relación con los municipios rurales, existen una serie de terrenos dependientes de sus instituciones municipales que, hoy son susceptibles de construcción y que no eran contemplados en las normas anteriores de leyes del Suelo. En su evolución urbanística, la falta de una normativa también les planteaba problemas de competencias, a veces de difícil resolución, a la hora de planificar las nuevas zonas urbanas. Actualmente, las competencias aparecen más claras en la nueva legislación. Aquí podemos señalar el grave deterioro producido en estas zonas, en cuanto se refiere de nuevo al patrimonio arqueológico, derivado de la inexistencia de prevención legislativa específica hacia él, por parte de los estamentos de obras públicas.

En suma, aunque actualmente estemos en disposición de poder utilizar la legislación vigente, con el fin de poner en marcha los mecanismos necesarios para llevar a cabo la protección del Patrimonio Histórico, siempre será necesaria una lectura correcta y detenida de los diversos aspectos legislativos, para interpretarlos de la manera más correcta y útil a nuestro Patrimonio Arqueológico.

\section{BIBLIOGRAFÍA}

AVIlÉs PereA, M. A, 1983: La participación de las entidades locales en la conservación y defensa de los restos arqueológicos. Primeras jornadas de Arqueología en las ciudades actuales. Zaragoza.

Barrero Rodríguez, C., 1990: La ordenación juridica del Patrimonio Histórico. Madrid. 
García Escudero, P., y Pendás García, B., 1986: El derecho del Patrimonio Histórico: teoría Madrid.

LEGISLACIÓN BÁSICA, 1982: Patrimonio Artístico, Archivos y Museos. 3. ${ }^{a}$ ed. Ministerio de Cultura.

LEY 7/1985, de 2 de abril, de Bases para el Régimen Local.

LEY 16/1985, de 25 de junio, del Patrimonio Histórico Español.

LEY 8/1990, de 25 de julio, sobre Reforma del régimen Urbanístico y Valoraciones del Suelo.

MARTín BuEnO, M., 1985: :Informe presentado a la Reunión del Consejo de Europa: Archeologie et Amenagement. Florencia, 1984". Análisis e Información Cultural, n. ${ }^{\circ} 24$.

REAL DECRETO 111/1986, de 10 de enero, de desarrollo parcial de la Ley 16/1985, de Patrimonio Histórico Español.

REAL DECRETO LEGISLATIVO 1/1992, de 26 de junio, por el que se aprueba el Texto Refundido de la Ley sobre el Régimen del Suelo y Ordenación Urbana. "BOE" n. ${ }^{\circ} 156$, de 30 de junio de 1992. 